\title{
Além das tradutoras canadenses: práticas feministas de tradução ontem e hoje
}

DOl: http://dx.doi.org/10.21165/el.v48i3.2331

\section{Pâmela Berton Costa' \\ Lauro Maia Amorim²}

\section{Resumo}

Neste artigo, apresentamos diversas tradutoras e práticas femininas e feministas de tradução ao longo do tempo. Partindo de uma contextualização sobre tradução como transformação regulada, refletimos sobre sua intersecção com os estudos feministas, especialmente a partir do fım do século XX. Apesar de termos as tradutoras canadenses dessa época como paradigma de tradução feminista, mostramos diversas tradutoras antes delas - no Brasil e no mundo - que consideraram a condição inferior da mulher na sociedade, muitas vezes usando suas traduções como forma de chamar a atenção para o problema. Tratamos também do contexto canadense de tradução feminista dos anos 1980, trazendo algumas de suas práticas e também de críticas a esse movimento. Por fim, abordamos alguns dos novos caminhos possíveis para os Estudos Feministas da Tradução, um campo que começa a se consolidar internacionalmente, mas que ainda carece de mais discussões.

Palavras-chave: estudos feministas da tradução; identidade; feminismos; tradução.

\footnotetext{
1 Universidade Estadual Paulista (UNESP), São José do Rio preto, São Paulo, Brasil; pamela.berton@unesp.br; http://orcid.org/0000-0003-3816-9031

2 Universidade Estadual Paulista (UNESP), São José do Rio preto, São Paulo, Brasil; lauro.maia@unesp.br; https://orcid.org/0000-0001-9141-9840
} 


\title{
Canadian translators and beyond: Feminist translation theories and practices then and now
}

\begin{abstract}
In this paper, we present several translators and their feminine and feminist practices of translation throughout time. From the concept of translation as a regulated transformation, we discuss its intersection with feminist studies, especially in the $20^{\text {th }}$ century. Although Canadian feminist translators of the eighties are until today paradigm of feminist translation, we show that various women translators - in Brazil and worldwide - before them had already considered the inferior position of women in society, by using their translations to call attention to this problem. We also discuss this Canadian feminist translation context of the eighties, explaining some of their practices and pointing out why they were criticized. Finally, we present some of the new possible approaches to Feminist Translation Studies, which is a field that needs more discussion.
\end{abstract}

Keywords: feminist translation studies; identity; feminisms; translation.

\section{Introdução}

Este artigo tem como propósito reunir e apresentar algumas das diversas reflexões de tradução feministas e práticas de tradução feitas por mulheres como forma de contribuir para a discussão que começa a ser feita no Brasil sobre o tema. Apesar de diversos textos terem sido publicados em português nos últimos anos a respeito dessa prática, como a tradução do artigo de Castro (2017), os artigos de Costa (e.g. 2012), Alencar e Blume (2015), Corrêa e Blume (2011) e a dissertação de Nemirovsky (2017), por exemplo, muito ainda precisa ser feito para que o debate alcance maior abrangência dentro dos Estudos da Tradução brasileiros. Costa (2006) inclusive ressalta que no meio acadêmico brasileiro é comum que os trabalhos feministas sejam alocados na área de "estudos de gênero", já que as palavras "feminismo" e "feminista" podem pressupor uma atitude radical que as pesquisadoras normalmente preferem evitar. Assim, segundo a autora, esses trabalhos conseguiram um certo espaço no cânone e são vistos como bons e confiáveis, o que, no entanto, impediu que esse mesmo cânone fosse desafiado.

Compreendemos, portanto, que os Estudos Feministas da Tradução são um tema controverso - tanto aqui quanto internacionalmente - e não nos negaremos a apresentar as críticas feitas a suas teorias. Todavia, acreditamos que as práticas feministas têm muito a contribuir para a área dos Estudos da Tradução - desde que sua abrangência se estenda. Para tanto, iniciamos nosso texto com uma breve contextualização da visão de tradução adotada neste trabalho e como ela se relaciona com as teorias feministas. Em seguida, apresentamos reflexões sobre mulheres tradutoras de séculos passados, sendo que muitas já pensavam e escreviam sobre a subalternidade feminina e tradutória 
antes mesmo de o movimento feminista existir ou se consolidar. Tratamos também das (controversas) tradutoras canadenses do final do século XX e, por fim, discutimos caminhos que têm sido trilhados pelas mulheres tradutoras (e alguns homens) que consideram sua prática como feminista, especialmente nas últimas duas décadas.

Nosso objetivo é reunir uma parte da informação sobre as teorias e práticas feministas a fim de instigar o interesse de outras/os pesquisadoras/es pelo tema. Como ficará claro na discussão proposta abaixo, muito tem sido feito na área dos Estudos Feministas da Tradução especialmente nas duas últimas décadas - em que o interesse pelo/s feminismo/s tem aumentado tanto dentro quanto fora dos estudos acadêmicos. No entanto, ainda é preciso consolidar essa disciplina de forma mais efetiva, aumentando o diálogo entre estudiosas/os ao redor do mundo - principalmente entre os países do Sul.

\section{Tradução como recriação}

Concebemos a tradução como uma transformação regulada, em que um texto original é interpretado e traduzido para outra língua por um sujeito tradutor. Quando historicamente o sujeito - e, portanto, a subjetividade - passa a ser considerado nos estudos humanos e linguísticos, há uma revolução na forma como esses estudos eram feitos até então, já que surge um questionamento sobre a impossibilidade da objetividade total nas práticas humanas. Como explica Arrojo (1996, p. 54-55), as diferentes tendências do pensamento crítico contemporâneo compartilham a preocupação de desconstruir e desnaturalizar:

[...] o embasamento que compõe nossas rotinas, concepções e visões de mundo, mostrando que tudo aquilo que nos acostumamos a encarar como natural é, na verdade, cultural e histórico e, portanto, determinado pelas circunstâncias e pelos interesses que o produzem; em suma, nada mais, nada menos do que uma construção humana, com todas as marcas, limitações e vieses inerentes a essa condição.

À luz dessas reflexões, o ato tradutório também não pode ser encarado como objetivo, mas como resultado de uma subjetividade inerente ao/à tradutor/a. Dessa forma, o texto traduzido será consequência de uma interpretação do sujeito e, portanto, uma transformação. É importante ressaltar que essa interpretação não é irrestrita, pois é limitada pela comunidade interpretativa que autoriza apenas algumas leituras como estratégias interpretativas aceitáveis (FISH, 1982) - ainda que esse número finito de leituras possíveis possa mudar com o tempo e que determinadas interpretações deixem de ser ou passem a ser vistas como válidas. Assim, não podemos atribuir qualquer significado que desejamos ao que lemos, pois essa atividade é regulada. 
Venuti (1995, p. 24) chamaa atenção para o fato de que "a subjetividadeéconstituída por determinações culturais e sociais que são diversas e até conflitantes, que medeiam todo uso de linguagem e que variam com cada formação cultural e com cada momento histórico"3. Assim, a formação do significado é uma construção social que depende dos sentidos que a comunidade leitora atribui às palavras em cada contexto. No caso da tradução, é preciso considerar o fato de que o/a tradutor/a trabalha entre culturas, muitas vezes lidando com relações de poder e opressão fortemente arraigadas. Especialmente se levarmos em conta não só a tradução literária, a qual grande parte das teorias costuma abordar, mas também os textos que lemos (especialmente os disponíveis on-line) e que, muitas vezes, não sabemos que são traduzidos.

O papel do/a tradutor/a, apesar de muitas vezes apagado ou desvalorizado, é fundamental nesse espaço de troca entre culturas e realidades que podem ser bem distintas. Penrod (1993, p. 39) salienta a necessidade de se pensar com cuidado nas escolhas feitas durante uma tradução, pois sempre nos é exigido "tomar uma posição" durante o ato tradutório em relação às outras culturas e línguas, por isso, devemos também estar atentos a qual será essa posição, refletindo sempre sobre o posicionamento assumido (ou não) e as relações de poder inerentes a ele - quer o/a tradutor/a esteja ciente delas ou as ignore completamente.

Assim, esse sujeito tradutor assume sempre uma posição que demanda responsabilidade, mesmo que não tenha consciência desse fato, como ressalta Simon (1996, p. 83, destaque da autora) ao defender que "as intenções de uma tradução nunca podem ser entendidas isoladamente, mas sempre em relação à estrutura social, política ou intelectual. [...] a tradução é em si mesma um ato intensamente relacional, que estabelece conexões entre texto e cultura". ${ }^{4}$ Essa relacionalidade que a tradução aciona mobiliza não só o contexto em que ela está inserida, mas também questões ligadas às identidades postas em jogo pelo texto traduzido.

Sendo a tradução inevitavelmente uma ação transformadora, é importante, então, provocar o "debate sobre a possibilidade de se pensar quais formas de transformação realmente queremos imprimir na prática tradutória do Outro" (AMORIM, 2014, p. 175, grifo do autor), ou seja, quais recriações serão aceitas dentro do contexto histórico-cultural no qual cada leitura e, consequentemente, cada tradução, se insere. Nesse espaço entre as

\footnotetext{
3 No original: "Subjectivity is constituted by cultural and social determinations that are diverse and even conflicting, that mediate any language use, and that vary with every cultural formation and every historical moment.".

4 No original: "[...] the intentions of translation can never be understood in isolation, but always in relation to a social, political or intellectual framework. [...] translation is in itself an intensely relational act, one which establishes connections between text and culture [...].".
} 
culturas e as identidades no qual a tradução e o/a tradutor/a se enquadram, as práticas feministas de tradução reconhecem o papel ativo transformador do sujeito, buscando justamente refletir sobre as formas de transformação que devem ou não ser aceitas como válidas.

Abaixo, partindo dessa concepção de tradução como atividade transformadora, que exige atenção quanto às posições assumidas dentro das relações de poder que ela mobiliza, tratamos de algumas das várias formas em que esse ato é executado em relação às mulheres. Não tratamos apenas da tradução como ativismo feminista, mas também das formas como ela tem sido performada por mulheres que não se encaixam no termo "feminista" da maneira como o concebemos hoje. Abordamos diferentes maneiras em que as relações entre mulher e tradução têm acontecido ao longo do tempo, tanto quando a tradução é feita para questionar os padrões dominantes e as relações de poder, quanto nos momentos em que mulheres tradutoras deliberadamente interferiram nos textos que traduziam para contestá-los ou refutá-los. O percurso adotado é o cronológico: abordamos primeiro as tradutoras de séculos passados que não se enquadram na noção contemporânea que temos de feminismo para, em seguida, falar das tradutoras abertamente feministas canadenses.

\section{As diversas práticas de tradução femininas e feministas}

\section{Mulheres tradutoras de séculos anteriores}

É comum, quando o tema da tradução feminista é abordado, referir-se somente às tradutoras canadenses dos anos 1980, normalmente citadas como as primeiras tradutoras feministas. Apesar de ser vista até hoje como paradigma, essa prática canadense - da qual trataremos mais adiante - não é a única e nem a primeira das reflexões feitas por mulheres tradutoras - muitas das quais começaram a ser resgatadas principalmente nos últimos cinquenta anos. Ainda que não se enquadrem na ideia contemporânea de feministas, há registros de textos que datam de várias décadas e até vários séculos atrás escritos por tradutoras que já refletiam sobre a condição de subalternidade tanto do sexo feminino, quanto da tradução, ou ainda que subvertiam e contestavam textos machistas.

Uma tradutora de destaque, por exemplo, foi Giuseppa Eleonora Barbapiccola, responsável pela tradução para o italiano da obra Principia Philosophiae, de Descartes, no século XVIII. Barbapiccola escreveu um longo prefácio defendendo tanto as mulheres quanto sua tradução - que inclusive levava seu nome completo junto ao título (CORRÊA; BLUME, 2011). Nesse prefácio, ela parte da constatação da inferioridade do sexo feminino na sociedade para combater os argumentos dos que concordam com essa posição e para exaltar mulheres escritoras e cientistas de outras épocas, ressaltando que as mulheres não são inferiores aos homens e exortando os/as leitores/as a valorizá-las e permitir que mostrem sua capacidade (CORRÊÁ; BLUME, 2011). Corrêa e Blume (2011) explicam 
que a tradução de Barbapiccola continha diversas notas explicativas e a tradutora foi tão reconhecida por tê-la publicado (quando tinha apenas 20 anos), que foi convidada a entrar para a Accademia dell'Arcadia, um espaço reservado praticamente apenas aos homens. Além disso, elas explicam que Barbapiccola também organizava debates para mulheres da época para difundir a filosofia cartesiana entre elas.

Outra mulher tradutora que merece destaque é Carmen de Burgos que, no começo do século XX, traduziu para o espanhol "Über den physiologischen Schwachsinn des Weibes", ${ }^{5}$ um texto de um conhecido neurologista austríaco que defendia a inferioridade intelectual das mulheres (CASTRO, 2011). Castro explica que, não querendo contribuir para a difusão de tais ideias misóginas, Burgos usou sua tradução justamente com o objetivo oposto do original, ou seja, para combatê-las, incorporando ao texto traduzido um prefácio escrito por ela e "inúmeras notas de rodapé com notas da tradutora em que refuta o texto, refutando-o também na série de ensaios de sua própria autoria que ela anexa à tradução a fim de deixar registrada a situação das mulheres de sua época" (CASTRO, 2011, p. 112). Essa tradutora, portanto, consciente de seu papel na disseminação de ideias, que podem ser opressoras, não se nega a traduzir um texto preconceituoso e machista com o qual não concorda - o que poderia fazer com que outro/a tradutor/a o fizesse -, mas escolhe rebatê-lo em seu próprio espaço. Esse é um exemplo de como a tradução é sempre uma transformação - em menor ou maior grau - e de como o sujeito tradutor se encontra entre as culturas, em um lugar perpassado pelas relações de poder - ainda que provavelmente não tenha consciência de todas as relações que podem ser mobilizadas nesse espaço.

A importância de tradutoras como Carmen de Burgos e Barbapiccola para as teorias da tradução é inegável, já que a prática tradutória dessas mulheres se desenvolve não como subalternidade a um original, mas como subversão desse original, como combate às ideias desse original. Assim, ambas propunham um tipo de tradução revolucionário para os padrões da época, que se mantinham fieis à ideia de transporte de significados de uma língua à outra. Ao não subscrever à ideologia dominante, Burgos e Barbapiccola praticaram aberta e declaradamente hijacking (FLOTOW, 1991), isto é, elas se apropriaram dos textos e os transformaram para que refletissem suas próprias intenções políticas e não as do autor. É importante pensarmos que o conceito de hijacking surge apenas nos anos 1990 para se referir às práticas feministas de tradução que interferiam deliberadamente no texto original. Isso significa que tradutoras como Burgos e Barbapiccola já agiam como as feministas contemporâneas muito antes de a tradução feminista ser vista como prática de ativismo e subversão da forma como a entendemos hoje.

5 Em espanhol, o texto se chama "La debilidad mental fisiológica de las mujeres", que pode ser traduzido por "A idiotice mental fisiológica das mulheres". 
Essas práticas não existiram apenas no exterior; no Brasil foram várias as tradutoras que também merecem ser destacadas, especialmente nos séculos XIX e XX, quando houve um considerável aumento da publicação de traduções para o português após a vinda da Família Real em 1808. Alencar e Blume (2015) citam diversos trabalhos, entre eles os de Francisca Izidora Gonçalves da Rocha, responsável pela tradução de obras de Lord Byron, e Carolina von Koseritz, que traduziu, entre outros, Goethe e Dickens. Além disso, as autoras também chamam a atenção para a tradução de textos que influenciaram os movimentos feministas brasileiros, como A solidariedade feminina, de Eugénie Potonié Pierre, traduzido por Josefina Álvares de Azevedo. Apesar de as práticas de muitas dessas mulheres não resultarem em traduções subversivas como as de Burgos e Barbapiccola, é importante reconhecer o impacto que elas tiveram na história da tradução brasileira e, especificamente no caso do texto traduzido por Josefina Álvares de Azevedo, nos movimentos feministas no país.

O caso de maior destaque para os movimentos feministas, entretanto, é o de Nísia Floresta que, em 1832, "traduziu" o manifesto feminista A Vindication of the Rights of Woman, de Mary Wollstonecraft, por Direito das mulheres e injustiça dos homens. Usamos traduziu entre aspas da mesma forma que Dépêche (2000) o faz, já que Nísia Floresta não usa apenas o texto original, juntando a ele ao menos outros dois textos ${ }^{6} e^{\text {omitindo }}$ diversas passagens, criando um novo original em português pela defesa das mulheres. Dépêche (2000, p. 168-169) destaca a importância de Nísia no cenário brasileiro e latinoamericano de começo de século, defendendo que

O caminho tomado assim, pela jovem brasileira, abre uma brecha no discurso e nas leis patriarcais, tomando a tradução como meio de acesso à palavra e ao mesmo tempo à divulgação das reivindicações das mulheres 'emudecidas'. A tradução, já em si crítica de texto, toma a forma de crítica do mundo dos homens e da afırmação da resistência das mulheres à sua hegemonia pela leitura e pela escrita.

Da mesma forma que A solidariedade feminina, o texto "traduzido" por Nísia Floresta teve grande importância para os movimentos de mulheres da época. Assim, ainda que a prática tradutória dessas mulheres não tenha resultado necessariamente em reflexões teóricas sobre os Estudos da Tradução, ela impactou o movimento feminista como um todo, o que está intrinsecamente ligado às práticas sociais. Por sua vez, esse impacto se traduz na forma como interagimos com as questões de feminino e de gênero de modo geral, o que, em um efeito cascata, inevitavelmente reflete nas teorias que estão sendo produzidas nas diversas áreas do conhecimento - como os Estudos da Tradução. Essa

6 Segundo Dépêche (2000, p. 167), Nísia Floresta se vale de traduções de trechos de De l'égalité des deux sexes, de François Poulain de La Berre, e Woman Not Inferior to Man, de uma desconhecida sob o pseudônimo de Sophia. 
é uma outra questão importante de ser apontada: a prática de tradução feminista não se restringe à criação de teorias ou à reflexão sobre o ato tradutório, mas também à própria tradução de textos feministas, criando pontes entre mulheres ao redor do mundo.

Além dessas estratégias feministas na área de Estudos da Tradução, existem várias outras, por exemplo, o resgate de textos de mulheres ignoradas pelos registros históricos. Com base nesses trabalhos, Robinson (1995) destaca tradutoras e teóricas inglesas ainda mais antigas que há muito tempo já subvertiam estratégias machistas de tradução nos séculos XVI e XVII. Segundo ele, as mulheres começaram a escrever sobre tradução na Inglaterra no século XVI. Essas mulheres (geralmente pertencentes a classes privilegiadas) passaram, Robinson (1995, p. 158) salienta, a erguer umas às outras a partir da "educação que seus pais progressivos lhes deram ao tematizar a subserviência como autonomia e a autonomia como subserviência - o original como cópia e a cópia como original ${ }^{7 "}$ - uma discussão recorrente nos Estudos da Tradução, mas que só foi debatida de forma mais ampla a partir da Virada Cultural em meados do século XX. Como as tradutoras que mencionamos até aqui, essas mulheres inglesas já trabalhavam algumas questões de subversão e subalternidade muito antes do século XX, no entanto, seus textos não são retomados por teóricos contemporâneos.

Robinson conclui que não é possível afirmar, com base no conhecimento que temos hoje, que essas mulheres eram mais modernas do que seus contemporâneos, no entanto, ressalta a necessidade de rever esses materiais que só recentemente começaram a ser explorados e que têm proporcionado tantas descobertas surpreendentes. Da mesma forma, Delisle (2002), no prefácio de um livro que organizou sobre perfis históricos de importantes tradutoras (como a primeira e única mulher de que se tem notícia que traduziu completamente a bíblia sozinha, por exemplo), salienta a necessidade de valorizar essa fonte de documentos escritos por mulheres. No que chamou de "um dos limites da história" (DELISLE, 2002, p. 8), o autor reconhece que há menos textos teóricos escritos por mulheres do que por homens, mas ressalta que isso se deve ao menor número de tradutoras do que de tradutores homens ao longo da história, já que as mulheres foram por muito tempo vistas como subalternas e inferiores.

É importante ressaltar, no entanto, que Delisle não defende que as mulheres retratadas no livro tenham sido feministas, pois isso seria uma falsa interpretação da história; ele apenas destaca a relevância dessas tradutoras que foram frequentemente ignoradas simplesmente por serem mulheres. Em uma reflexão similar, Robinson (1995) evidencia o fato de que é fácil acreditar que teorias da tradução começaram a ser escritas por mulheres apenas no final dos anos 1970, já que a definição de teoria é normalmente

7 No original: "[...] the education their progressive parents have allowed them by thematizing subservience as autonomy and autonomy as subservience - the original as copy and the copy as original.". 
restrita a uma explicação sistemática de todos os aspectos de uma área de estudo, e vários dos textos escritos por essas mulheres abordam apenas algum ponto específico da prática tradutória. Ainda assim, todas essas tradutoras de séculos passados têm em comum o fato de que foram precursoras das tradutoras feministas de hoje, sendo que muitas dessas mulheres já produziam não só traduções, mas também teorias sobre essas traduções, como mostramos com os vários exemplos neste texto, mesmo que a história tenha se encarregado de esquecê-las.

A esse "esquecimento" do legado e da importância das mulheres, Duarte (2019) dá o nome de memoricídio feminino, isto é, o deliberado apagamento da ação das mulheres ao longo do tempo. Esse conceito é muito importante para a reflexão que propomos porque a atividade feminista das últimas décadas tem focado em várias frentes de ação. Uma delas, como mencionado anteriormente, é a recuperação de trabalhos feitos por mulheres que não receberam, na época da publicação, a atenção que teriam recebido se tais textos fossem escritos por homens. A partir do movimento feito por escritoras e críticas literárias como Rich (1972), por exemplo, que colocou em evidência nosso relacionamento patriarcal com os textos que canonizamos, um resgate desses textos escritos por mulheres é iniciado em meados do século XX. E é justamente através desse esforço das feministas do final dos anos 1970 e 1980 em questionar o cânone de modo geral que a memória dessas mulheres escritoras começa a ser recuperada.

Esse resgate se expande do apagamento feminino da história literária para outras áreas afins, como as traduções e reflexões acerca da prática tradutória, por exemplo. Sobre esse resgate, Castro (2017) inclusive chama a atenção para a errônea ideia de que as mulheres só começaram a escrever sobre teorias da tradução na época das tradutoras canadenses nos anos 1980, defendendo ainda que é contraproducente ver somente estas últimas como paradigma, pois isso restringe o desenvolvimento frutífero de outras áreas de pesquisa. Assim, é necessário entender o que foi esse movimento canadense e porque ele é visto até hoje como a primeira e única forma de tradução feminista.

\section{0 contexto canadense de escrita e tradução feminista}

O movimento feminista, iniciado no final do século XIX e princípio do século XX, provocou diversas mudanças na teoria social e nas ciências humanas (HALL, 2001). Segundo Castro (2017, p. 219), uma das principais contribuições dos feminismos (no plural, para reconhecer a multiplicidade de facetas do movimento) "está na revisão crítica a que têm submetido as diferentes disciplinas científicas e humanistas, questionando seu caráter supostamente neutro e objetivo e revelando que atendiam (em uma medida diferente) aos critérios patriarcais". A partir da reflexão feminista, portanto, a tradução também não pode ser vista como neutra, pois, se todas as disciplinas atendem aos critérios dominantes, também o ato tradutório é influenciado. Dessa forma, muitos/as autores/as defendem a ideia de que o simples fato de o/a tradutor/a não aderir de forma deliberada a uma 
ideologia não-patriarcal implica alinhar-se inconscientemente à ideologia dominante/ machista, que é dominante tanto numericamente, quanto por apoiar os interesses da classe dominante (CASTRO, 2017).

Nesse contexto, Flotow (1997) explica o surgimento, no Canadá, de um grupo de escritoras que, através da subversão da linguagem, pretendia fazer visível o feminino nos textos. Segundo ela, essa escrita radical feminina era experimental e buscava minar e subverter a língua convencional mantida pelas instituições. As escritoras feministas canadenses "viam a língua como um instrumento de opressão e submissão das mulheres que precisava ser reformada e talvez até substituída por uma nova língua das mulheres. Elas então assumiram a posição radical de atacar a língua em si" (FLOTOW, 1997, p. 14). Esse tipo de escrita influenciou os Estudos da Tradução na medida em que o ato de traduzir esses originais politizou diversas/os tradutoras/es, sendo que uma boa parte da discussão teórica sobre gênero e tradução feita nessa época "foi iniciada pelas mulheres tradutoras que primeiro lidaram com esses textos" (FLOTOW, 1997, p. 24). No caso canadense, a subversão se dá inicialmente no campo linguístico, em oposição às práticas de tradução subversivas das tradutoras de séculos passados que apresentamos anteriormente.

Como consequência desse movimento, houve um aumento significativo na tradução de textos feministas e nas reflexões acerca do processo tradutório. Um dos exemplos mais citados em textos dessa época, como no de Flotow (1991, p. 69-70), é a comparação entre duas traduções para o inglês, uma feminista e uma conservadora, da mesma frase, em francês, de uma peça de teatro de um coletivo feminista canadense dos anos 1970: "Ce soir, j'entre dans l'histoire sans relever ma jupe"8. A tradução mais conservadora e mais colada à literalidade das palavras seria "this evening I'm entering history without pulling up my skirt". A feminista, por sua vez, seria "this evening I'm entering history without opening my legs"10, que explicitaria o que o original só deixava subentendido, isto é, o fato de que uma mulher está entrando para a história sem precisar oferecer favores sexuais a ninguém, por seu próprio mérito e esforço.

A discussão provocada por traduções como essas diz respeito aos limites que uma tradução feminista engajada, nos moldes do que era visto como tradução feminista no Canadá na época, deveria ou não respeitar. Nesse artigo, Flotow defende que a discussão não é sobre qual tradução é melhor, mas qual contexto e quais práticas permitem que uma tradução feminista como a dessa frase, que torna explícito o que estava implícito, seja aceitável e até desejável. A própria Flotow (1991) ressalta que esse mesmo exemplo já havia sido usado outras vezes, sendo que ela o tirou de um texto de Godard - a quem

8 Esta noite, eu entro/estou entrando para a história sem levantar minha saia.

9 Esta noite, entro/estou entrando para a história sem levantar minha saia.

10 Esta noite, entro/estou entrando para a história sem abrir as minhas pernas. 
chama de uma das primeiras tradutoras feministas canadenses. Flotow chama a atenção para esse movimento de usar o mesmo exemplo várias vezes, vendo-o como uma das evidências de que, mesmo no Canadá dos anos 1990 - que hoje ainda é paradigma de tradução feminista - poucos/as tradutores/as eram sensíveis às questões de gênero.

Essa reflexão merece destaque porque aproxima as propostas de questionamento sobre gênero e mulher dos dias atuais e a (supostamente) ampla discussão que foi feita no Canadá de finais do século XX. Ainda hoje, muitas vezes exageramos os movimentos feministas anteriores, acreditando que tiveram uma abrangência maior do que efetivamente alcançaram, tomando como garantidas e consolidadas discussões que, na verdade, muitas vezes ficaram restritas a pequenos grupos. Por isso é tão importante aumentar o volume de textos a respeito das diferentes práticas feministas relacionadas à tradução, especialmente em países como o Brasil, onde boa parte dessas teorias apenas começou a ser mais debatida nos últimos vinte anos, estando longe de serem questões estabelecidas.

Além das reflexões sobre a prática tradutória em si no contexto canadense, com exemplos práticos das tradutoras que estavam lidando com os textos experimentais na época, também foram escritos muitos textos que, na esteira de discussões que estavam sendo feitas nos Estudos da Tradução devido à Virada Cultural, questionam o próprio papel subalterno da tradução. Chamberlain (1988), por exemplo, no texto "Gender and the Metaphorics of Translation", muito retomado por estudiosas/os da área até hoje, chama a atenção para o fato de que as metáforas usadas para se referir à tradução normalmente também inferiorizam a mulher. A autora destaca a sexualização, ao longo da história, da tradução, dando-lhe um caráter feminino e inferior a um original masculino e supostamente superior. Entre vários exemplos citados, Chamberlain destaca a já consagrada expressão les belles infidèles, em que há um contrato implícito entre a tradução (mulher) e o original (marido, pai, autor). Se "traído" devido à beleza da mulher, a legitimidade da prole desse original é definida, assim como nas relações sociais humanas, através do reconhecimento da paternidade, não da maternidade. A autora defende que essa associação com o feminino-inferior versus masculino-superior é determinada pelas relações de poder na divisão de gênero.

A partir dessas reflexões que a tradução dos textos experimentais canadenses provocou e espelhando-se nessas escritoras, muitas tradutoras passaram a adotar estratégias feministas não só com os textos experimentais, mas também com aqueles que liam como machistas, buscando explicitar e ridicularizar as vozes opressoras. Ao traduzir para o inglês La Habana para un Infante Difunto, de Guillermo Cabrera Infante, Levine, por exemplo, usou diversas técnicas, descritas por ela no prefácio e em artigos posteriores à publicação, para chamar a atenção do/a leitor/a e ridicularizar a misoginia da obra - 
como na frase "ningún hombre puede violar a una mujer"11 (que, segundo ela, teria como tradução literal para o inglês "no one man can rape a woman"), para "no wee man can rape a woman"12 (LEVINE, 1992, p. 83), na tentativa de diminuir e ironizar estupradores. Esse uso de notas e de textos de apoio, como prefácios, nos quais as tradutoras explicitam e justificam suas escolhas é uma das principais características desse movimento e muito do que foi produzido nessa época diz respeito principalmente às reflexões que as próprias tradutoras faziam enquanto traduziam.

Entretanto, as estratégias adotadas por essas tradutoras estão longe de ser consenso, tendo sido muito criticadas, especialmente a partir dos anos 1990. Arrojo (1994, p. 149), por exemplo, defende que "essas tradutoras parecem cair em uma nova versão dos mesmos 'infames dois pesos e duas medidas' que podem ser encontrados em nossas tradicionais, 'masculinas' teorias e concepções de tradução"13. Para os/as que concordam com essa visão, o resultado da tradução feminista repetiria as mesmas contradições da discussão sobre gênero, como a existência de uma suposta "escritura feminina" em oposição à masculina, um argumento muito usado pelas tradutoras feministas e que só reforçaria os mesmos padrões dominantes que pretendiam combater.

Esse movimento de tradução feminista passou a sofrer as mesmas críticas que o próprio feminismo de segunda onda ${ }^{14}$ sofreu, a de que equipararia as mulheres em uma vivência feminina única, como se todas as dificuldades relacionadas ao gênero fossem as mesmas em todas as partes do mundo e todas as mulheres sofressem as mesmas violências por serem do sexo feminino, desconsiderando sociedades de configuração diferente às do Ocidente - especialmente de países do Norte. Segundo Branaman (2011, p. 32), os/as críticos/as dessa segunda onda do feminismo alegavam que as feministas, apesar da diversidade do movimento, "compartilhavam a falha de não conseguirem se

11 Nenhum homem pode estuprar uma mulher.

12 Nenhum homem pequeno/insignificante pode estuprar uma mulher.

13 No original: "[...] such female translators seem to fall into another version of the same 'infamous double standard' that can be found in our traditional, 'masculine' theories and conceptions of translation."

14 Brevemente, o/s movimento/s feminista/s ocidental/is pode/m ser dividido/s em três ondas: a primeira, do final do século XIX e início do século XX, foi a sufragista; a segunda, entre os anos 1960 e 1970, resistia contra a discriminação sexual e buscava oportunidades iguais para homens e mulheres; a terceira, a partir dos anos 1980/1990, pode ser subdividida em várias correntes menores e muito plurais, sendo que muitas delas incorporaram à discussão de gênero outras questões além da suposta existência feminina comum, como a homossexualidade, o pós-colonialismo, as discussões sobre "raça" (BRANAMAN, 2011; MILLS, 2002). Atualmente, considera-se que estaríamos em uma quarta onda do feminismo, mas essa nomenclatura ainda não é consenso. 
comunicar com as experiências e os interesses de mulheres que não fossem brancas, de classe média, heterossexuais ou cidadãs de países do Hemisfério Norte"15.

Apelidado pejorativamente de "Feminismo Branco", esse movimento tinha em comum com a tradução feminista canadense o fato de que buscava igualdade entre homens e mulheres, mas falhava em conseguir compreender a complexidade da existência como mulher em um contexto fora do Ocidente branco de classe alta. Reimóndez (2017), por exemplo, explica como as análises das metáforas sexistas da tradução feitas por Chamberlain foram apresentadas como universais e adaptáveis a todas as línguas quando na verdade não o são. No contexto galego, segundo a autora, elas não se aplicam, já que a tradução não é associada ao feminino (secundária), mas ao masculino, por ser considerada um conceito chave na construção da identidade (patriarcal) nacional, após os quatro séculos em que não se podia escrever em galego. Dessa forma, podese perceber a partir desse exemplo que teorias que foram tratadas como universais dentro da reflexão acadêmica no final do século XX na verdade não se aplicam a todas as realidades e é a partir dessa crítica que surgem os novos caminhos da discussão feminista dentro dos Estudos da Tradução.

No entanto, apesar de controversa, é inegável a repercussão da prática feminista canadense nos Estudos da Tradução, sendo que muito do que foi e é produzido até hoje relacionando gênero e prática tradutória parte de resultados dos questionamentos e das reflexões feitas por essas tradutoras nessa época. A (re)descoberta de textos escritos por mulheres que haviam sido negligenciados pela história, por exemplo, só foi possível graças ao esforço das escritoras e tradutoras feministas do final do século XX. Além disso, muitos textos traduzidos também começaram a ser questionados. Henitiuk (1999) destaca as interpretações enviesadas que o/a tradutor/a não atento/a faz e que, como consequência, geram textos que aderem in/conscientemente à visão de mundo dominante (e machista). A esse "tradutor patriarcal", especialmente no caso da tradução de textos escritos por mulheres, a autora chama de falotradutor, isto é, "um intérprete inadequado da escrita das mulheres devido a uma observável dependência de pressuposições falocêntricas arraigadas" (HENITIUK, 1999, p. 473), sendo que esse questionamento da prática tradutória é um inegável desdobramento das ações dos movimentos feministas dentro da literatura e da crítica literária.

Por serem mais atentas ao gênero e justamente por criticarem as práticas patriarcais que in/conscientemente o/a tradutor/a imprime em sua prática, as teorias feministas foram (e são) acusadas de restringirem a atividade tradutória, pois estariam tirando a liberdade do/a tradutor/a - uma crítica que os movimentos sociais em prol das minorias

15 No original: "[...] they shared a common failure to speak to the experiences and interests of women who were not white, middle class, heterosexual, or citizens of countries of the global North.". 
recebem constantemente por serem "politicamente corretos" e tornarem o mundo "mais chato". No entanto, Massardier-Kenney (1997, p. 65) rebate essas acusações ao defender que "canalizar a tradução através de um enfoque feminista pode salientar aspectos de um texto que tinham sido negligenciados ou até mesmo omitidos"16, o que enriqueceria - e não restringiria - a prática tradutória de maneira geral.

Cabe à tradução feminista, portanto, o papel de revisar textos escritos ou traduzidos por mulheres, como mostram os trabalhos de Robinson e os perfis escritos para o livro organizado por Delisle, e de chamar a atenção dos/as tradutores/as contemporâneos para as práticas que silenciam o feminino, como propõem Henitiuk e MassardierKenney. Segundo Ergun (2013, p. 272), "a tradução feminista é uma práxis que concebe a tradução como um ato criador de significado, que é político e criativo - além de ter poder transformador -, e o/a tradutor/a como um ativo agente de mudança sociopolítica"17. Mas, nos termos atuais, o que seria essa prática feminista? As canadenses ainda são vistas como paradigma, mas para onde caminha a tradução feminista hoje e o que tem sido feito nessa área a partir das portas que as tradutoras dos anos 1980 e 1990 abriram e dos tetos de vidro que quebraram?

\section{A tradução feminista hoje: novos caminhos possíveis}

Em uma pesquisa sobre a tradução feminista contemporânea em língua alemã, Wolf(2005, p. 22) explica que, apesar de diversas linhas de pesquisa estarem sendo desenvolvidas na área, "como disciplina, os estudos feministas da tradução ainda estão apenas começando no que diz respeito à sua institucionalização"18. O aspecto que mais chamou a atenção do grupo responsável pelo estudo foi o fato de que as pesquisas nesse campo têm sido feitas somente através de iniciativas individuais de mulheres estudiosas, não só nos países de língua alemã, mas também na Europa de modo geral, sendo que essas iniciativas raramente são parte de projetos específicos, ainda que a interdisciplinaridade seja uma característica comum. A nosso ver, essa falta de projetos amplos - e com apoio financeiro - que sejam direcionados para os estudos feministas é uma evidência da marginalidade dos Estudos Feministas da Tradução mesmo nos dias de hoje. No Brasil, por exemplo, a resistência aos estudos da área se estende ao uso da palavra feminista, como explicado na introdução deste trabalho, já que a maioria das estudiosas que trabalham com feminismo e feminino preferem usar palavras relacionadas a gênero

\footnotetext{
16 No original: "Channeling translation through a feminist approach can bring out aspects of a text that had been overlooked or even suppressed [...].".

17 No original: "Feminist translation is a praxis that conceives translation as a political and creative act of meaning making with transformative power, and the translator as an active situated agent of sociopolitical change.".
}

18 No original: "[...] as a discipline feminist translation studies is only in its beginnings as far as its institutionalization is concerned.". 
ao invés de assumirem academicamente uma postura ativista feminista por receio de não serem levadas a sério.

Uma das formas de reverter esse quadro é também uma das principais características dos novos caminhos para as práticas de tradução feminista, isto é, a busca por mais vozes para se juntarem à discussão. Essa busca se baseia justamente em uma resposta às críticas feitas ao feminismo de segunda onda, já que as novas teorias feministas têm como base o reconhecimento da diferença entre as vivências como mulher ao redor do mundo. Godayol (2005), por exemplo, defende que é preciso aceitar que a "categoria mulher" é fluida para libertar esse conceito das noções binárias que normalmente estruturam os discursos, reconhecendo-a como aberta a revisão e (re)significação. Assim, não se pode mais tratar de um único feminino, mas de diversos fatores que atravessam esse feminino, como posição social, país de origem, cor da pele, além de fatores como sexualidade e gênero (cis/trans). Nesse mundo globalizado de constante troca entre as culturas e de "viagem de teorias" no qual vivemos atualmente, o papel da tradução para a disseminação dessas diferentes realidades femininas é fundamental.

Hoje, os feminismos são concebidos como múltiplos, no plural, e como uma prática transnacional, ou seja, que extrapola as fronteiras e busca conectar mulheres de diversos países, aumentando o número de experiências sendo discutidas. No campo da tradução, essas discussões já começam a apresentar resultados tímidos, sendo que organizadoras/ es e editoras/es de livros e revistas científicas que tenham como tema estudos feministas aplicados à tradução têm tentado incluir textos de diferentes países e não só do Norte ou do Ocidente. Como Castro e Ergun (2017, p. 1), que iniciam a apresentação do livro Feminist Translation Studies, organizado por elas e um marco na área, atestando que "o futuro dos feminismos está no transnacional e o transnacional é feito através da tradução"19. Apesar de reconhecerem que os capítulos presentes no livro numericamente ainda privilegiam uma discussão mais centrada na realidade ocidental, mesmo que as editoras tenham tentado não reproduzir essa hegemonia, ambas declaram que, em um "exercício de honestidade intelectual, assumimos total responsabilidade por nossos pontos cegos e convidamos os/as leitores/as a se juntarem ao diálogo, trazendo consigo o que veem a partir do lugar que ocupam" (CASTRO; ERGUN, 2017, p. 5).

Esse tem sido o sentimento comum às conferências e publicações que lidam atualmente com as questões feministas ligadas à tradução. Em eventos como Translating Women e Feminism's and/in Translation, ambos em outubro de 2019, o discurso é de dar voz a mulheres que falam de lugares não hegemônicos, como de países com menor visibilidade, ou de um lugar de marginalidade (mulheres negras ou homossexuais, por exemplo). Esse discurso tem se transformado em atitudes concretas de tentativas de cooperação que

19 No original: "The future of feminisms is in the transnational and the transnational is made through translation.". 
se traduzem na já citada prática de incluir outros pontos de vista que não se resuma ao branco, ocidental e anglófono. Como exemplo, além do livro organizado por Castro e Ergun, há o número especial de tradução feminista da revista internacional sobre tradução Mutatis Mutandis, que sairá no primeiro semestre de 2020, "Towards Transnational Feminist Translation Studies", que especificou em sua chamada para publicação que o número seria transnacional, sendo que algumas das linhas temáticas se referem especificamente à hegemonia da língua inglesa a partir de um ponto de vista crítico e à necessidade de diálogo entre vozes não hegemônicas vindas do Sul.

Dessa forma, a necessidade de incluir vivências distintas é um tema recorrente nos mais recentes textos sobre a tradução feminista. O capítulo escrito por Reimóndez no livro organizado por Castro e Ergun, por exemplo, trata da necessidade de ampliar a discussão para além da hegemonia da língua inglesa. A autora, inclusive, chama a atenção para o fato de que a própria nomenclatura usada (transnational, international ou global) para tratar do espaço de troca entre os feminismos é baseada no inglês como ponto de partida. Nesse texto, em que traça um percurso sobre o contexto da língua galega e sua posição não-hegemônica, Reimóndez (2017, p. 43) explica como o trabalho na ONG Implicadas no Desenvolvemento, que fundou em 1998 em Tamil Nadu, na Índia, a fez questionar as histórias que nos são contadas sobre as outras mulheres e as formas como os estereótipos viajam e influenciam as vivências da/o outra/o. Ainda que reconheça as facilidades do inglês como "língua franca" na difusão de teorias feministas, Reimóndez defende seu uso apenas como uma língua intermediária, uma mediadora na troca de textos e experiências entre mulheres de diferentes culturas e falantes de línguas nãohegemônicas.

Costa e Alvarez (2014, p. 560) também abordam o tema da língua inglesa como dominante e se perguntam como escapar "das economias epistemológicas que institucionalizaram os centros acadêmicos anglófonos como as redes de inteligibilidade da teoria e, mais especificamente, da teoria feminista" 20 , ressaltando as relações entre teoria e poder. As autoras destacam trabalhos de teóricas latino-americanas, como os da própria brasileira Costa, membro do corpo editorial da Revista Estudos Feministas, da Universidade Federal de Santa Catarina, que publica traduções de textos feministas do inglês para o português e também artigos inéditos de autoria brasileira. Como Reimóndez, Costa (2012, p. 56) também destaca como essa viagem de teorias de línguas não-hegemônicas para o inglês é incompleta, defendendo que esse fato revela "um dos muitos fatores ocultos que interferem nas práticas de tradução cultural e na articulação de feminismos transnacionais, pós-coloniais". Nesse ponto reside ainda uma lacuna na área.

20 No original: "[...] the epistemological economies that have institutionalized the Anglophone academic centers as the grids of intelligibility for theory and, more specifically, for feminist theory.". 
Esse é um dos principais desafios enfrentados tanto pelos Estudos Feministas da Tradução quanto pelos feminismos de modo geral hoje, pois, ainda que busquem aumentar as vozes participantes da discussão em um espaço transnacional, muito ainda precisa ser feito para que esse espaço seja efetivamente global e não apenas dominado pelas teorias ocidentais/escritas em inglês. Parece-nos que, apesar de cientes do problema, ainda encontramos os mesmos obstáculos que as feministas de segunda onda, isto é, ainda precisamos ampliar o debate para além do mundo branco ocidental - anglófono e do Norte. Costa (2006, p. 73) ressalta que, para evitar que a discussão seja centrada apenas na direção "Ocidental-para-o-Resto", as feministas de modo geral precisam de alianças que desenvolvam um diálogo "do-Sul-para-o-Sul" e que dependam de processos contínuos de tradução como uma forma de trabalhar com a/o outra/o, ao invés de excluí-la/o. O quadro geral dos Estudos Feministas da Tradução parece estar caminhando para essa direção de maior unidade e sororidade entre as estudiosas da área nos últimos anos, como atestam os congressos e as publicações mencionadas anteriormente.

Tratando mais especificamente do contexto brasileiro e latino-americano, uma das principais intersecções entre os feminismos e os Estudos da Tradução se dá justamente no campo do pós-colonialismo e na desconstrução das amarras de dominação Norte-Sul. No mesmo artigo em que aponta como as teorias do Sul não viajam para o Norte, o que constitui uma relação bastante assimétrica, Costa (2012, p. 45) defende que, sendo o/s feminismo/s uma atividade política, "urge trazer as contribuições feministas para a mesa da ceia pós-colonial e, num gesto de traição (presente em todo ato de tradução), subverter sua gastronomia patriarcal e descolonizá-la". Assim, é preciso dar voz à realidade (ainda subalterna) das feministas do Sul, aumentando não só o espaço de discussão feminista, mas também o espaço de trocas entre realidades não-hegemônicas, como é o caso da latino-americana. Vemos como primordial o ato de voltar o olhar para nosso próprio contexto, explicitando nossas similaridades e diferenças, crescendo juntas/os. Nesses espaços, a tradução tem papel fundamental para desenvolver essa compreensão.

\section{Considerações finais}

Neste artigo, tratamos de algumas tradutoras, suas práticas feministas de tradução e suas traduções de teorias feministas ao longo dos séculos, abordando não só as canadenses dos anos 1980, mas também suas (pouco reconhecidas) precursoras e algumas de suas atuais predecessoras. Nosso trabalho não se propôs exaustivo, na verdade, quisemos instigar no/o leitor/a o interesse pelo que tem sido produzido na área, reunindo aqui alguns dos caminhos trilhados recentemente. Como pesquisadores de uma cultura não-hegemônica (a brasileira) que ainda tem pouca inserção no campo dos Estudos Feministas da Tradução - e de maneira tímida, nem sempre politizada (vide o uso de "estudos de gênero" ao invés de "estudos feministas") -, vemos como um caminho promissor para a área as produções feitas justamente por pesquisadoras/es de países e culturas não-hegemônicas, do Sul, não anglófonas. Reconhecemos a importância 
e o impacto das tradutoras feministas canadenses, mas também acreditamos na necessidade de seguir adiante com a discussão, como têm feito muitas/os estudiosas/ os ao redor do mundo.

Assim, existe um imenso leque de possibilidades para a tradução feminista que está sendo desenvolvida nas últimas décadas, passando pelo resgate histórico de textos escritos por mulheres, pela (re)tradução de textos que foram falotraduzidos, pela tradução de teorias feministas escritas em outras línguas, pela troca entre mulheres falantes de línguas diferentes e que só é possível através da tradução, entre diversas outras opções. Em nosso mundo cada vez mais conectado, em que os textos muitas vezes perdem sua origem e que a tradução tem um papel fundamental, acreditamos que uma das principais contribuições dos feminismos é o olhar crítico que nos permite ver concepções falocêntricas arraigadas e questioná-las. Os rumos dos Estudos Feministas da Tradução ainda são incertos e não sabemos quais promessas serão cumpridas e quantas mudanças efetivamente serão feitas.

No entanto, vemos a atualidade como profundamente impactada pela efervescência tanto das discussões feministas quanto das relacionadas ao gênero de maneira mais ampla, sendo este um momento muito propício para que os Estudos Feministas da Tradução sejam capazes de aumentar o volume das vozes não-hegemônicas, estendendo a discussão para além de pequenos grupos de tradutoras engajadas - o que já está sendo feito graças às redes sociais e às listas de contato entre pesquisadoras. No caso específico do Brasil, o número de pesquisas na área tem aumentado, sendo que há trabalhos desenvolvidos em várias universidades, como os de Claudia Lima Costa, Elena Manzato e Beatriz Barboza, na Universidade Federal de Santa Catarina, por exemplo; o de Camila Hespanhol na Universidade de Brasília, além da nossa própria pesquisa que ainda está sendo desenvolvida. Assim, o interesse pelas relações entre tradução e feminismos tem se intensificado no país e acreditamos que a pesquisa conseguirá se solidificar a ponto de estabelecer um campo de Estudos Feministas da Tradução no Brasil. Ressaltamos, então, a importância de produzir estudos e reflexões sobre o tema justamente para que o volume das vozes aumente e a discussão se torne ampla de maneira mais efetiva, pois muito temos a aprender com um espaço de debate entre as culturas sobre o/s feminino/s.

\section{Agradecimentos}

O presente trabalho só foi possível com apoio da Coordenação de Aperfeiçoamento de Pessoal de Nível Superior - Brasil (CAPES) - Código de Financiamento 001 e da FAPESP (Processo no 2018/17944-5). 


\section{REFERÊNCIAS}

ALENCAR, M. E. S.; BLUME, R. F. Mulheres traduzindo literatura no Brasil nos séculos XIX e XX. Ci. \& Tróp., Recife, v. 39, n. 1, p. 97-115, 2015.

AMORIM, L. M. Tradução como diáspora: as vozes da poesia afro-americana no Brasil. In: ESTEVES, L.; VERAS, V. Vozes da tradução: éticas do traduzir. São Paulo: Humanitas, 2014. p. 149-176.

ARROJO, R. Fidelity and the gendered translation. TTR, Quebec, v. 7, n. 2, p. 147-162, 1994.

ARROJO, R. Os estudos da tradução na pós-modernidade, o reconhecimento da diferença e a perda da inocência. Cadernos de Tradução, Florianópolis, v. 1, n. 1, p. 53-69, 1996.

BRANAMAN, A. Feminism and Identity. In: ELLIOTT, A. (ed.). Routledge Handbook of Identity Studies. London: Routledge, 2011. p. 30-49.

CASTRO, O. Traductoras gallegas del siglo XX: reescribiendo la historia de la traducción desde el género y la nación. In: SANTAEMILIA, J.; von FLOTOW, L. (Eds.). MonTI 3 - Woman and Translation: Geographies, Voices and Identities. San Vicente del Raspeig: Espagrafic, 2011. p. 107-130.

CASTRO, O. (Re)examinando horizontes nos Estudos Feministas da Tradução: em direção a uma terceira onda? Tradução Beatriz Regina Guimarães Barboza. TradTerm, São Paulo, v. 29, p. 216-250, 2017.

CASTRO, O.; ERGUN, E. Feminist translation studies: local and transnational perspectives. New York and London: Routledge, 2017.

CHAMBERLAIN, L. Gender and the Metaphorics of Translation. Signs, Chicago, v. 13, n. 3, p. 454-472, 1988.

CORRÊA, R. D.; BLUME, R. F. Prefácio de tradução ou manifesto feminista? Interdisciplinar, São Cristóvão, v. 13, p. 185-195, 2011.

COSTA, C. L. Lost (and Found?) in Translation: Feminisms in Hemispheric Dialogue. Latino Studies, v. 4, p. 62-78, 2006. 
COSTA, C. L. Feminismo e tradução cultural: sobre a colonialidade do gênero e a descolonização do saber. P: Portuguese Cultural Studies, Utrecht, v. 4, n. 1, p. 41-65, 2012.

COSTA, C. L.; ALVAREZ, S. E. Dislocating the Sign: Toward a Translocal Feminist Politics of Translation. Signs, Chicago, v. 39, n. 3, p. 557-563, 2014.

DELISLE, J. (org.). Portraits de traductrice: sous la direction de Jean Delisle. Ottawa: Presses de l'Université d'Ottawa, 2002.

DÉPÊCHE, M.-F. A tradução feminista: teorias e práticas subversivas Nísia Floresta e a Escola de Tradução Canadense. Textos de História, Brasília, v. 8, n. 1/2, p. 157-188, 2000.

DUARTE, C. L. Memoricídio: o apagamento da história das mulheres na literatura e na imprensa. Aracaju, UFSE, 2019. (Mesa redonda no XVIII Seminário Internacional Mulher e Literatura).

ERGUN, E. Reconfiguring Translation as Intellectual Activism: The Turkish Feminist Remaking of Virgin: The Untouched History. Trans-Scripts. v. 3, p. 264-289, 2013.

FISH, S. What makes an interpretation acceptable? In: FISH, S. Is there a text in this class? Cambridge: Harvard University Press, 1982. p. 338-355.

FLOTOW, L. Translation and Gender: Translating in the 'Era of Feminism'. Manchester (UK): St. Jerome Publishing, 1997.

FLOTOW, L. Feminist Translation: Contexts, Practices and Theories. TTR. v. 4, n. 2, p. 6984, 1991.

GODAYOL, P. Frontera Spaces: Translating as/like a Woman. In: SANTAEMILIA, J. (ed.). Gender, sex and translation: The manipulation of identities. Manchester, UK: St. Jerome, 2005. p. 9-14.

HALL, S. A identidade cultural na pós-modernidade. Tradução Tomaz Tadeu da Silva e Guacira Lopes Louro. Rio de Janeiro: DPeA, 2001.

HENITIUK, V. Translating Woman: Reading the Female through the Male. Meta, v. XLIV, n. 3, p. 469-484, 1999. 
LEVINE, S. J. Translation as (Sub)Version: on Translating Infante's Inferno. In: VENUTI, L. (ed.). Rethinking Translation. London: Routledge, 1992.

MASSARDIER-KENNEY, F. Towards a Redefinition of Feminist Translation Practice. The Translator, Manchester, v. 3, n. 1, p. 55-69, 1997.

MILLS, S. Third-way feminist linguistics and the analysis of sexism. In: IGALA 2 CONFERENCE, 2002, Lancaster. Disponível em: http://extra.shu.ac.uk/daol/articles/ open/2003/001/mills2003001-paper.html. Acesso em: 18 jul. 2018.

NEMIROVSKY, J. V. A tradução feminista. In: NEMIROVSKY, J. V. A ética da intervenção ideológica na tradução. 2017. Dissertação (Mestrado em Letras/Estudos da Linguagem) - Pontifícia Universidade Católica, Rio de Janeiro, 2017. p. 27-62.

PENROD, L. Translating Hélène Cixous: French Feminism(s) and Anglo-American Feminist Theory. TTR, Quebec, v. 6, n. 2, p. 39-54, 1993.

REIMÓNDEZ, M. We need to talk... To each other. On polyphony, postcolonial feminism and translation. In: CASTRO, O.; ERGUN, E. Feminist translation studies: local and transnational perspectives. New York and London: Routledge, 2017.

RICH, A. When We Dead Awaken: Writing as Re-Vision. College English, v. 34, n. 1, p. 18-30, 1972.

ROBINSON, D. Theorizing Translation in a Woman's Voice: Subverting the Rhetoric of Patronage, Courtly Love and Morality. The Translator, London, v. 1, n. 2, p. 153-175, 1995.

SIMON, S. Gender in Translation: Cultural Identity and the Politics of Transmission. London: Routledge, 1996.

TRANSLATING WOMEN. 1st. London, 2019.

VALENCIA/NAPOLI COLLOQUIUM ON GENDER AND TRANSLATION: FEMINISMS AND/IN TRANSLATION. 3rd. Valencia, Espanha, 2019.

VENUTI, L. The Translator's Invisibility: a History of Translation. London: Routledge, 1995.

WOLF, M. The Creation of a "Room of One's Own": Feminist Translators as Mediators between Cultures and Genders. In: SANTAEMILIA, J. (ed.). Gender, sex and translation: The manipulation of identities. Manchester, UK: St. Jerome, 2005. p. 15-25. 